\title{
Controle e fiscalização eletrônica: o uso da tecnologia no trânsito no interior da Bahia
}

Control and electronic surveillance: the use of technology in the traffic in the interior of Bahia

\section{Control e inspección electrónica: el uso de tecnología en el tráfico en el interior de Bahía}

Edson Celino Rodrigues Filho ${ }^{1}$ https://orcid.org/0000-0002-7067-6140

Almiralva Ferraz Gomes ${ }^{2}$ https://orcid.org/0000-0002-5440-2115

Rita de Cássia Oliveira Lima Alves ${ }^{3}$ https://orcid.org/0000-0002-9090-8762

\footnotetext{
${ }^{1}$ Universidade Estadual do Sudoeste da Bahia. Vitória da Conquista, Bahia, Brasil. E-mail: edinhu.r@gmail.com

${ }^{2}$ Departamento de Ciências Sociais Aplicadas da Universidade Estadual do Sudoeste da Bahia, Vitória da Conquista, Bahia, Brasil. E-mail: almiralva@gmail.com

${ }^{3}$ Departamento de Ciências Sociais Aplicadas da Universidade Estadual do Sudoeste da Bahia. Vitória da Conquista,

Bahia, Brasil. E-mail: rcassialimaa@gmail.com
}

Recebido em: 12/01/2021

Aceito para publicação em: 21/03/2021

\section{Resumo}

O processo de intensificação da urbanização trouxe muitas repercussões para a vida em sociedade e para o trânsito, como a popularização dos automóveis, que fez crescer, inclusive, o número de acidentes. Os acidentes podem ser causados por inúmeros fatores e o seu videomonitoramento surgiu como uma medida capaz de ampliar o alcance da fiscalização. Este artigo pretende analisar a percepção do poder público e dos cidadãos de uma cidade de médio porte do interior da Bahia, acerca da efetividade da fiscalização eletrônica promovida pelo Projeto de Videomonitoramento do Trânsito, implantado pela Prefeitura Municipal. De natureza empírica e do tipo descritivoexploratória, os resultados indicaram que o videomonitoramento é uma ferramenta que pode auxiliar na melhoria da fluidez e segurança do trânsito.

Palavras-chave: Controle. Fiscalização Eletrônica. Trânsito.

\begin{abstract}
The process of intensifying urbanization has had many repercussions for life in society and for traffic, such as the popularization of automobiles, which has even increased the number of accidents. Accidents can be caused by numerous factors and their video surveillance has emerged
\end{abstract}

Geopauta, Vitória da Conquista ISSN: 2594-5033, V. 5, n.1, 2021, e8057

Este é um artigo de acesso aberto sob a licença Creative Commons da CC BY normas ABNT 
as a measure capable of expanding the scope of inspection. This article intends to analyze the perception of public authorities and citizens of a medium-sized city in the interior of Bahia, regarding the effectiveness of electronic surveillance promoted by the Traffic Monitoring Video Project, implemented by the City Hall. Empirical and descriptive-exploratory, the results indicated that video monitoring is a tool that can help improve traffic fluidity and safety.

Keywords: Control. Electronic Inspection. Traffic.

\section{Resumen}

El proceso de intensificación de la urbanización ha tenido muchas repercusiones para la vida de la sociedad y para el tráfico, como la popularización de los automóviles, que incluso ha aumentado el número de accidentes. Los accidentes pueden ser causados por numerosos factores y su videovigilancia ha surgido como una medida capaz de ampliar el alcance de la inspección. Este artículo pretende analizar la percepción de los poderes públicos y ciudadanos de una ciudad mediana del interior de Bahía, sobre la efectividad de la vigilancia electrónica impulsada por el Proyecto de Video de Monitoreo de Tránsito, implementado por el Ayuntamiento. Empírico y descriptivo-exploratorio, los resultados indicaron que el monitoreo por video es una herramienta que puede ayudar a mejorar la fluidez y seguridad del tránsito.

Palabras clave: Control. Inspección electrónica. Tráfico.

\section{Introdução}

Atualmente, o Brasil ocupa o quinto lugar entre os países do continente americano com maior número de vítimas fatais de trânsito, conforme Ministério da Saúde (BRASIL, 2015). A maioria das causas referem-se à desorganização do trânsito, más condições dos veículos e vias públicas, comportamento inadequado dos usuários, ou mesmo, reduzida punição imposta aos infratores.

O Código de Trânsito Brasileiro (CTB) regulamenta o trânsito de veículos e de pedestres nas vias públicas. Trata-se, portanto, do principal agente normativo do trânsito no Brasil. A partir das regras impostas pelo CTB, os órgãos fiscalizadores se encarregam de aplicar a lei emanada pelo Código, sendo dever dos condutores de veículos e pedestres se adequarem às suas regras, de forma que todos possam transitar com tranquilidade e segurança nas vias urbanas. 
Os recentes avanços tecnológicos permitem uma amplitude maior do uso da tecnologia como auxílio ao controle e fiscalização do trânsito, os radares de velocidade, redes de monitoramento de video e medidas que possibilitam aos órgãos fiscalizadores de trânsito autuar condutores imprudentes em tempo real ou não. Os radares já são utilizados no trecho da BR 116, que atravessa Vitória da Conquista, cidade de médio porte do interior baiano. Contudo, tal dispositivo restringia-se a fiscalização na referida rodovia federal. Em 2015, um projeto de videomonitoramento de veículos foi implantado em Vitória da Conquista, o que permitiu não só a identificação das imprudências mais recorrentes cometidas pelos condutores como também o aprofundamento dos estudos na área, ao construir um banco de dados para estudos que permitem aprimorar a mobilidade urbana. O presente estudo, assim, pretende analisar as percepções do poder público e do cidadão conquistense acerca da implantação da fiscalização eletrônica no trânsito de Vitória da Conquista.

\section{Trânsito: surgimento, evolução e repercussões}

O CTB, em seu $1^{\circ}$ artigo, parágrafo 1, traz a seguinte definição de trânsito: “Considera-se trânsito a utilização das vias por pessoas, veículos e animais, isolados ou em grupos, conduzidos ou não, para fins de circulação, parada, estacionamento e operação de carga ou descarga" (BRASIL, 1997). Dado o conceito, traça-se, assim, um breve histórico sobre a evolução do trânsito enquanto atividade humana e como tal prática auxiliou no desenvolvimento da sociedade primitiva até o surgimento das civilizações recentes. Conforme Franz e Seberino (2012), o meio de locomoção mais antigo foi a caminhada, pois o homem já usara de seu próprio esforço para transportar seus bens e se deslocar de um lugar a outro. Após, o homem se deu conta da possibilidade de domesticar os animais e usar sua força motriz para alcançar locais mais distantes e carregar uma maior quantidade de peso. Seguidamente, a partir da invenção da roda, houve uma grande revolução dos meios de transporte. A medida, portanto, que se aperfeiçoava a roda, novos veículos também eram criados para 
atender as necessidades de locomoção e transporte do homem. Assim, os antigos caminhos eram transformados em estradas, permitindo o acesso mais rápido entre cidades distantes. Conforme Hoffmann, Cruz e Alchieri (2003) e Vasconcelos (2017), no fim do século XIX, um importante marco para o desenvolvimento do trânsito e da humanidade concretizou-se e, por conseguinte, desencadeou os problemas de trânsito a outro patamar: a invenção do primeiro automóvel, patenteado em janeiro de 1886 por Karls Benz. Em contraponto, ao tratar da invenção do automóvel, Vasconcellos (2017, p. 6) discorre que, “com a criação do automóvel e o aumento da circulação nas cidades surgem os primeiros problemas modernos de trânsito e, consequentemente, uma legislação a respeito". Evidencia-se, assim, a preocupação contínua com o tema, pois, mesmo antes da invenção do automóvel, em 1870, Londres já ostentava o número de 460 mil carruagens, que produziram, até aquela data, algo em torno de 3.200 feridos e 237 mortos, motivando as autoridades a implantar, no mesmo ano, o primeiro semáforo de que se tem notícia (VASCONCELOS, 2017, p. 8).

No Brasil, em 1897, com a chegada do primeiro automóvel, foi protagonizado por Olavo Bilac o primeiro acidente de trânsito, ocorrido, mais precisamente, na cidade do Rio de Janeiro, onde o poeta colidiu com uma árvore, após tomar emprestado o carro de seu amigo abolicionista José do Patrocínio (GAZIR, 1998). À partir da metade da década de 1950, com o plano de crescimento nacional proposto por Juscelino Kubitscheck e o aumento dos investimentos em infraestrutura rodoviária, a popularização dos automóveis se expandiu, contribuindo com maior volume de veículos presentes nas cidades e estradas, elevando-se, assim, o número de problemas no trânsito, sobretudo acidentes e congestionamentos, provocados por automóveis e motocicletas (FRANZ; SEBERINO, 2012).

Diversos problemas contribuem para dar ao trânsito uma imagem desfavorável perante a sociedade, tais como os congestionamentos e, como defende Vasconcelos (2017), esses aspectos podem estar atrelados a ideia de movimento, condição fundamental do trânsito. Diante da situação conflitante entre "permitir o movimento" 
e "possibilitar o acesso", os estudos de Vasconcelos (2017, p. 17) separam tais conflitos em duas categorias gerais: o "conflito físico" e o "conflito político". O primeiro se configura na "impossibilidade física de acomodar simultaneamente, no mesmo espaço, os movimentos gerados pelas atividades das pessoas", já o segundo trata da "posição diferenciada das pessoas com relação ao processo produtivo e seus resultados à sociedade, e pelos interesses diversos e conflitantes que daí decorrem".

Segundo dados da Organização das Nações Unidas (ONU) de 2011, os acidentes de trânsito mataram cerca de 1,25 milhão de pessoas por ano, tornando-se a nona causa de óbitos de indivíduos em todo o mundo e ainda sendo a razão de ferimentos de 20 a 50 milhões de pessoas a cada ano. Tais indicadores preocupam, pois geram diversos problemas de saúde pública, não somente pelos casos de óbito ou pelos traumas físicos e mentais resultantes de tais incidentes, mas também pela oneração dos custos diretos e indiretos causados à sociedade. (BASTOS; ANDRADE; CORDONI, 1999).

Embora seja desafiador calcular-se o valor de uma vida humana, os custos que pesam diretamente sobre os envolvidos, bem como o custo repassado à sociedade pelos acidentes de trânsito podem ser estimados. Em pesquisa realizada pelo Instituto de Pesquisa Econômica Aplicada (IPEA), conclui-se que “[...] os acidentes em rodovias custam à sociedade brasileira cerca de $\mathrm{R} \$ 40,0$ bilhões por ano, enquanto os acidentes nas áreas urbanas, em torno de $\mathrm{R} \$ 10$ bilhões, sendo que o custo relativo à perda de produção responde pela maior fatia desses valores, seguido pelos custos hospitalares" (BRASIL, 2015, p. 13).

Quanto às razões que contribuem para um número tão alto de acidentes e custos associados, Ferreira e Tebaldi (2004) consideram o ser humano como o grande causador dos acidentes. Para os pesquisadores, no entanto, o fator humano não pode ser estudado isoladamente, de modo que “O homem tem sua história, personalidade, interesses, necessidades e busca satisfazê-la, gerando conflitos no trânsito, pois interpreta as regras estabelecidas conforme sua visão de mundo" (FERREIRA; 
TEBALDI, 2004, p. 2). Sendo assim, a educação para o trânsito pode evitar conflitos no trânsito, uma vez que é necessário aos indivíduos instrução adequada para compreender o tipo de comportamento a ser adotado nas vias.

Ao estimular, assim, a conscientização das boas práticas no trânsito, os cidadãos apresentam, cada vez mais, uma conduta positiva, em especial as que são apresentadas pelo CTB. Evidencia-se que, com a vigência do CTB, em 1998, reduziuse, significativamente, os casos de acidentes de trânsito em vias urbanas e rodovias, se comparadas com o ano anterior, devido à criação de leis mais duras e multas mais caras. Essa redução, porém, não se manteve por muito tempo, possivelmente, “[...] pela falta de uma fiscalização efetiva, com aplicação severa das punições previstas em lei e, também, pelo atraso no recebimento das multas, que trouxe de volta a sensação de impunidade, fazendo com que os motoristas e pedestres voltassem a se comportar de maneira inadequada no trânsito" (BASTOS; ANDRADE; CORDONI, 1999, p. 7). Assim, ao que parece, o ato de fiscalizar e autuar, se for o caso, exerce papel importante para o cumprimento das normas de trânsito. Considerando o disposto no art. 280, parágrafo $2^{\circ}$, que afirma que toda e qualquer infração deve ser “[...] comprovada por declaração da autoridade ou do agente da autoridade de trânsito, por aparelho eletrônico ou por equipamento audiovisual, reações químicas ou qualquer outro meio tecnologicamente disponível, previamente regulamentado pelo CONTRAN" (BRASIL, 1997), a presente pesquisa propôs-se a estudar o caso do videomonitoramento (VDM) em Vitória da Conquista, cujo projeto foi implantado recentemente. Discorre-se, entáo, a seguir, sobre os recursos eletrônicos de fiscalização adotados pelos órgãos responsáveis pela aplicação das leis de trânsito, especificamente os radares e câmeras de VDM, como forma de controle, sobretudo, o social.

\section{Controle social}

A palavra Controle, segundo o dicionário Michaellis (2018), etimologicamente derivada da língua francesa - Contrôle - possui diversos significados, dentre eles: 
"Ato de dirigir qualquer atividade, fiscalizando-a e orientando-a do modo mais conveniente" (CONTROLE, 2018). Uma derivação do tema é o Controle Social, que tem seu fundamento na sociologia e se define como o "processo pelo qual uma sociedade ou grupo procura assegurar a obediência de seus membros por meio dos padrões de comportamento existentes" (CONTROLE, 2018). Ou ainda, "como uma série de mecanismos ou instrumentos utilizados pela sociedade, ou por um grupo social, com o objetivo implícito ou explícito de controlar os comportamentos (ou diferentes manifestações destes) e ações diferentes ao seu sistema" (HAERTER, 2012, p. 3). Ante o exposto, pode-se sustentar que o respeito, ou falta dele, às regras impostas pela sociedade estão em consonância com os mecanismos de controle social existentes. Merton (1968) identifica como tais estruturas impactam diretamente a conduta dos indivíduos em sociedade, ao afirmar que,

[...] um equilíbrio efetivo entre as duas fases da estrutura social é mantido enquanto a satisfação aumenta para indivíduos que se conformam a ambas, isto é, à satisfação alcançada dos objetivos e à satisfação obtida diretamente dos modos institucionalmente canalizados do esforço (MERTON, 1968, p. 2).

Tais fatores podem ser associados ao termo "desvio social" que, para Haerter (2012, p. 23), configura-se como o ato de agir fora do padrão de normalidade imposto pela sociedade, tornando-se "um produto da relação indivíduo-cultura-sociedade que, ao determinar suas regras, acaba, também, criando seus desvios". No Brasil, pode-se associar a ideia de "desvio social" à prática do "jeitinho brasileiro", a qual está visceralmente arraigado na sociedade brasileira e remonta sua origem no período do Brasil-colônia (ALCADIPANI; MOTTA, 1999).

DaMatta (2015) refere-se ao Brasil como um país marcado por uma sociedade altamente hierarquizada, envolta em relacionamentos impessoais sempre voltados ao topo da pirâmide e para fora do sistema convencional, o que o torna um terreno fértil para o desenvolvimento do "jeitinho". Para alguns, os mecanismos de controle social não se aplicam a tal perfil, devido a posição que ocupam na sociedade (ROSS, 2017). O controle social, entretanto, também é uma via de mão-dupla. Segundo Silva (2002), foi Geopauta, Vitória da Conquista, ISSN: 2594-5033, V. 5, n.1, 2021, e8057 
graças à reforma gerencial, estabelecida na administração pública na transição do século XX para o século XXI, que nasceu a possibilidade do uso do controle social, baseado na busca pelos resultados. "Na língua portuguesa, a palavra tem um sentido de dominação e, talvez por essa causa, o controle é muitas vezes visto como um procedimento inconveniente e inoportuno" (SILVA, 2002, p. 3).

O controle social é pouco visto como um tema familiar, pois, mesmo com a presença de diversos mecanismos (Ministério Público, Tribunal de Contas, portais de transparência, mídia, entre outros) contidos na sociedade brasileira, verifica-se um despreparo do cidadão para usar tais instrumentos de controle (SILVA, 2002). O estudo do controle social é, desta forma, realizado por diferentes abordagens, segundo Haerter (2012): Estruturalista, Funcionalista, Fenomenológica e Interacionista. Na abordagem Estruturalista, a sociedade é vista como um organismo total segmentado em vários grupos sociais e organizações que se relacionam entre si e reagem ao ambiente externo. A abordagem Funcionalista sofreu duras críticas em sua trajetória acadêmica devido ao fato de não levar em consideração a heterogeneidade de costumes presentes em cada estrutura social, mesmo naquelas que parecem similares. Sobre a abordagem Fenomenológica refere-se ao significado dado pelos membros de determinada sociedade sobre as experiências apresentadas a eles cotidianamente, ou seja, "a maneira pela qual as normas sociais, valores, padrões de comportamento entre outros aspectos da consciência humana são internalizados e interpretados pelas pessoas no mundo em que vivem" (HAERTER, 2012, p. 9). Finalmente, o cerne da abordagem Interacionista trata da "compreensão das diferentes formas pelas quais as pessoas reagem a determinadas situações" (HAERTER, 2012, p. 11). Por fim, pode-se afirmar então que,

[...] a manifestação do comportamento humano não é determinada por uma "sociedade", nem por uma "instituição", nem pelos seus "valores", é sim influenciada por estes através de sentimentos, de preferências, de gostos pessoais, em última instância, pelos diferentes "eus". Neste sentido, a ação social dos indivíduos, assim como as diferentes manifestações de seus comportamentos são consequência do 
modo pelo qual estes indivíduos interpretam a realidade e o contexto social no qual estão inseridos. (HAERTER, 2012, p. 12).

Assim, conforme afirma Haerter (2012, p. 11), “a própria existência de regras subentende-se a possibilidade de seu descumprimento e, por sua vez, um estímulo à defesa da sociedade, o que ocorre através de mecanismos de controle". Contudo, a transgressão às regras de trânsito nem sempre pode ocorrer como o esperado. Sendo assim, é muito frequente a utilização de mecanismos eletrônicos cuja função é identificar alguns atos contrários às leis de trânsito, afinal a "[...] atualização dessa vigilância por esses objetos técnicos contribui para moldar um tipo de sociedade denominada [...] de sociedade do controle" (BRICALLI; ZANOTELLI, 2016, p. 134). Desta forma, a próxima seção tratará da adoção de dispositivos eletrônicos de fiscalização no trânsitoatravés de sistemas de VDM urbano.

\section{Dispositivos eletrônicos de fiscalização no trânsito}

Verifica-se um cenário caótico no trânsito, na maioria das vezes, influenciado por falhas no planejamento urbano, precariedade das vias públicas e imprudência dos condutores e pedestres. De acordo com Sousa (2008, p. 6), “observa-se um crescimento acelerado do número de veículos privados, devido à necessidade de se locomover com rapidez produzindo um cenário indesejado e insustentável quanto aos deslocamentos diários". A fiscalização eletrônica se mostra, assim, como uma medida cada vez mais recorrente na atualidade para tentar inibir e registrar casos de transgressão das leis de trânsito e manter um mínimo de civilidade.

O uso de dispositivos eletrônicos de fiscalização nasce, portanto, da necessidade de aumentar a segurança e condicionar a mobilidade urbana, e redução de infrações no trânsito. Para Alves e Ferreira (2014), a mobilidade urbana deve ser analisada tanto pela ótica política quanto pela técnica, pois o crescimento urbano deve dar atenção às necessidades de locomoção dos indivíduos. Os autores apresentam ainda, estudo sobre a sustentabilidade do trânsito como forma de melhorar a mobilidade urbana e a 
qualidade de vida da população, a fiscalização eletrônica relcionado um grupo dos moderadores de tráfego (trafficcalming) existentes. Porém, o emprego dos moderadores de tráfego não é uma preocupação recente (BARTHÉLEMY et al., 2019; NEMADE, 2016). Esses se originaram na Europa, entre as décadas de 1960 e 1970, quando as intervenções feitas eram basicamente a alteração do layout e a instalação de redutores de velocidade nas vias, para estimular a conscientização dos condutores. Em uma breve retrospectiva sobre o uso da tecnologia na fiscalização do trânsito brasileiro, Sousa (2008) afirma que, em agosto de 1992, o primeiro mecanismo desse tipo instalado no Brasil foi um Redutor Eletrônico de Velocidade (REV), também conhecido como lombada eletrônica, usado para reduzir a velocidade de tráfego de veículos em pontos considerados críticos. A partir de então, esses dispositivos, que preveem moderar a velocidade de trânsito nas vias para evitar acidentes, seguiram sendo implantados em diversos estados brasileiros.

A alínea III, do art. 24, do CTB, investiu poder aos municípios para "implantar, manter e operar o sistema de sinalização, os dispositivos e os equipamentos de controle viário" (BRASIL, 1997). Foi possível aos municípios, assim, participar da gestão do trânsito com maior autonomia, ao tornarem-se responsáveis pela aplicação das multas e investimento da arrecadação em medidas de educação e fiscalização. Vitória da Conquista, cidade de médio porte, localizada na região Sudoeste da Bahia, experimentou tardiamente os primeiros instrumentos de fiscalização eletrônica, de que se tem conhecimento, em caráter permanente, apenas após a privatização da rodovia federal BR-116, no ano de 2013. Tal rodovia cruza a cidade em toda sua extensão norte-sul. Segundo a VIABAHIA, concessionária responsável pela gestão da rodovia no Estado, no ano de 2015, foram instalados os primeiros radares fixos em Vitória da Conquista, mais precisamente próximos aos trechos onde a rodovia passa pelo anel rodoviário que atravessa e circunda a zona urbana da cidade. Cupolillo (2006) e Lopes e Porto (2007) afirmam que os estudos realizados nas rodovias onde há 
radares fixos revelam que tais ferramentas não atingem a eficácia pretendida, visto que essas ações possuem caráter local, restringindo-se ao trecho fiscalizado.

Outro tipo de fiscalização eletrônica presente em Vitória da Conquista é o VDM de veículos. Em um projeto implementado recentemente, mais precisamente em julho de 2018, a fiscalização do trânsito passou a ser realizada através de câmeras de vigilância de alta resolução, instaladas em pontos estratégicos de algumas vias, cujo fim foi identificar focos de problemas no trânsito. Como um dos bnefícios, os agentes de trânsito seriam liberados para atuar em outras áreas da cidade e educar os condutores a partir da fiscalização e punição eficaz permitida pelo registro em vídeo das condutas inadequadas no trânsito (PMVC, 2018).

O uso de mecanismos de vigilância nas cidades tem sido cada dia mais comum, o que gera um debate, muitas vezes polêmico, quanto ao seu uso (BARTHÉLEMY et al., 2019). Em sua maioria, seu emprego público ou privado tem relação com a questão da segurança. Segundo Castro e Pedro (2013, p. 353), “esses dispositivos configuram relações nas quais práticas e ações cotidianas, que até então poderiam passar despercebidas, ganham visibilidade". A utilização desses mecanismos pode, assim, auxiliar a mudança de comportamento dos indivíduos que passam a ter consciência da visibilidade dos seus atos. No entanto, existem aqueles que discordam de tal uso e justificam que o VDM cerceia a liberdade do indivíduo.

Para Scaringella (2001), o uso da tecnologia é um forte aliado na luta contra a violência e imprudência no trânsito. Para o autor,

A cultura brasileira não tem sido generosa com atitudes preventivas. No trânsito não é diferente. Além disso, quando se fala em problemas no trânsito, geralmente reduz-se o tema às questões de fluidez, quando o maior desafio é a segurança, ou seja, buscar reduzir o número e a gravidade dos acidentes (SCARINGELLA, 2001, p. 59).

O uso dos mecanismos de fiscalização eletrônica, portanto, geralmente está vinculado à ideia de um trânsito mais humano, dando prevalência à vida em detrimento da fluidez. Contudo, deve-se avaliar os efeitos alcançados pelo relacionamento junto à sua população, dando-lhe voz a esse importante tema. 


\section{Procedimentos metodológicos}

Para alcançar o intento de analisar a percepção do poder público e dos cidadãos de Vitória da Conquista acerca da efetividade da fiscalização eletrônica promovida pelo Projeto de Videomonitoramento do Trânsito, optou-se por uma pesquisa do tipo descritivo-exploratória e de natureza empírica, pois “[...] o significado dos dados empíricos depende do referencial teórico, mas estes dados agregam impacto pertinente, sobretudo ao facilitarem a aproximação prática" (DEMO, 1994, p. 37). Quanto a técnica, optou-se pelo estudo de caso, pois este apresenta-se como método apropriado ao detalhamento e profundidade do fenômeno em estudo, na medida que se pretende "lidar com uma ampla variedade de evidências - documentos, artefatos, entrevista e observações" (YIN, 2001, p. 27).

Considerando que o universo de condutores e pedestres é indefinido, a amostra da população se deu de maneira não probabilística. Aplicou-se, assim, o critério de acessibilidade em um lapso temporal de 30 dias. A amostra dos funcionários seguiu o critério de amostra por conveniência, para selecionar "os elementos a que se tem acesso, podendo estes, de alguma forma, representar o universo" (GIL, 2011, p. 94).

Para compreender o comportamento adotado pelas pessoas nos trechos monitorados e não-monitorados, realizou-se, ainda, observação não-participante. A escolha dos locais seguiu o critério aleatório em um primeiro momento e planejado em um segundo momento. A justificativa para tal escolha se deu pela facilidade na “obtenção de dados sem produzir querelas ou suspeitas nos membros das comunidades, grupos ou instituições que estão sendo estudadas" (GIL, 2011 p.101). Tais dados foram recolhidos em captura de vídeo em cerca de 9 horas de filmagens em diversos locais da cidade, distribuídos em três turnos (manhã, tarde, noite), durante 15 dias consecutivos, em fevereiro de 2019.

Para descrever o Projeto de Monitoramento de Trânsito, realizou-se entrevistas com as pessoas ligadas ao Programa. Entrevistaram-se, assim, três funcionários lotados na Secretaria de Mobilidade Urbana. A escolha dessa modalidade de coleta 
ocorreu devido ao seu caráter exploratório, pois, conforme Quaresma (2005), é “[...] utilizada para o detalhamento de questões e formulação mais precisas dos conceitos relacionados. [...] o entrevistado tem liberdade para discorrer sobre o tema sugerido. É uma forma de poder explorar mais amplamente uma questão" (BONI; QUARESMA, 2005, p. 74).

Com a finalidade de verificar a percepção dos condutores e pedestres sobre o trânsito, aplicaram-se cem questionários de forma on-line, através da plataforma Google Forms, e transmitido por e-mail e aplicativos de comunicação social. Utilizaram-se, ainda, dados secundários disponibilizados pela Secretaria de Mobilidade Urbana para se verificar a localização de instalação das câmeras de VDM distribuídas pelas vias da cidade até a data do estudo.

O tratamento dos dados foi do tipo quanti-qualitativo. Para Demo (1994, p. 7), "a ciência prefere o tratamento quantitativo porque ele é mais apto aos aperfeiçoamentos formais: a quantidade pode ser testada, verificada, experimentada, mensurada". A análise qualitativa proporciona, porém, tratamento mais profundo, principalmente de dados das entrevistas e observações, ao se investigar o que está por detrás dos fenômenos que pouco se conhecem, sobretudo quanto aos "detalhes intrincados" de um fenômeno que as metodologias quantitativas nem sempre oferecem (ALENCAR, 1999).

\section{Análise e discussão dos resultados}

O órgão municipal de trânsito é amplamente conhecido pelos cidadãos como SIMTRANS, muito embora oficialmente seja denominado Secretaria Municipal de Mobilidade Urbana (SEMOB), órgão encarregado pela administração do trânsito em todo o trecho urbano de Vitória da Conquista e também pela operação do Sistema de Videomonitoramento do Trânsito da cidade. 
Os dados coletados em campo confirmaram que existe um sistema de informações que reúne e cataloga os dados das ocorrências registradas diariamente nas vias, pois segundo o Agente de Trânsito,

Cada processo é um pouco diferente. Tem o auto de infração, que é o ato administrativo que o agente de trânsito lavra na via. Nesse ato, todos os dados são coletados com um tablet eletronicamente, para encontrar o proprietário do veículo, os dados do condutor e enviar a NAI (Notificação de Auto de Infração) para a residência. Quando é feito o registro da ocorrência, é gerado um protocolo e posterior a isso a gente faz uma coleta de dados para alimentar uma planilha que vai dizer: quais são as vias que acontecem mais acidentes, quais são os principais veículos envolvidos nesses acidentes, qual a gravidade do acidente, condição da via, por exemplo. (INFORMAÇÃO VERBAL) ${ }^{4}$

O Coordenador de Trânsito afirma que o sistema de informações mantido pela Coordenação de Trânsito foi de grande valia no momento de implantação e ampliação do Projeto de Videomonitoramento, porém, devido ao caráter recente do Projeto, "na verdade, a gente está começando a receber esses dados agora né? Então primeiro precisamos começar a entender como podemos ajustar melhor a fiscalização" (COORDENADOR Z). Com isso, evidenciou-se que, até o momento das entrevistas, não havia disponível nenhum dado estatístico capaz de comparar a situação antes e depois da implantação do Projeto.

Até o dia da realização da entrevista, em 25 de fevereiro de 2019, havia um total de 18 câmeras de alta resolução instaladas nas vias do centro da cidade. Todas eram capazes de cobrir um ângulo de $360^{\circ}$ e possuíam zoom de alta qualidade que permitia focar nitidamente as infrações e placas dos veículos num perímetro de até $1 \mathrm{~km}$. Vale salientar que o equipamento não pertence ao Poder Público.

[...] um processo licitatório para definir qual empresa faria a instalação e manutenção dos aparelhos. [...] todo esse equipamento é alugado, uma vez que o Poder Público não tem condições de manter esse equipamento em pleno funcionamento e ainda adquirir peças extras e

\footnotetext{
${ }^{4}$ Entrevista I (Março de 2019): entrevista realizada com o Agente de Trânsito X. Entrevistador: Edson Celino Rodrigues Filho.
}

Geopauta, Vitória da Conquista, ISSN: 2594-5033, V. 5, n.1, 2021, e8057

Este é um artigo de acesso aberto sob a licença Creative Commons da CC BY normas ABNT 
não dispor de pessoal para reparar os equipamentos. (INFORMAÇÃO VERBAL) $)^{5}$

Todavia, ainda que haja o contato de outras pessoas com o equipamento, conforme o Supervisor Y: “toda a operação dos equipamentos é feita pelo SIMTRANS, não há envolvimento de terceiros. O próprio agente (de trânsito) tem o controle das câmeras e faz a movimentação das mesmas". Com isso, mantém-se a segurança e a privacidade dos dados colhidos.

Quanto à rotina diária do Projeto de Videomonitoramento, foi informado que a fiscalização só ocorre pelo período de 12 horas por dia. Ou seja, há uma escala de sete agentes de trânsito que trabalham em turno de 6 horas ao dia. Atualmente, cada agente é responsável pela fiscalização de, no máximo, quatro trechos monitorados. Fixou-se, porém, o limite máximo de cinco monitores para cada agente. Ainda segundo o Supervisor Y: “[...] dos 65 agentes que temos hoje, todos vão acabar passando por lá, em forma de rodízio, a não ser um ou outro tenha dificuldades com o sistema e peça para sair, mas a grande maioria passa por lá". Sobre a viabilidade da fiscalização ser realizada 24 horas ao dia, um dos porta-vozes da Coordenação de Trânsito informou:

[...] ainda estamos em fase embrionária. Então, se hoje estamos com 7 agentes em cada turno, se houver o aumento para 24 horas de monitoramento esse número teria mais que dobrar. Porém, acredito que não tenha necessidade dessa amplitude de fiscalização no momento, pois não justifica o investimento para fiscalizar horários em que a incidência de ocorrências é baixa. (INFORMAÇÃO VERBAL) ${ }^{6}$

Sobre o armazenamento dos dados, esclareceu-se que as imagens de vídeo se mantêm no sistema pelo período de até sete dias, devido às limitações técnicas de armazenamento de dados. Quanto ao número de pessoas envolvidas no Projeto de Videomonitoramento, não há um número definido, exceto os agentes que lidam diretamente com as imagens capturadas pelas câmeras, pois toda a Coordenação de

\footnotetext{
${ }^{5}$ Entrevista II (Março de 2019): entrevista realizada com o Supervisor de Trânsito Y. Entrevistador: Edson Celino Rodrigues Filho.

${ }^{6}$ Entrevista II (Março de 2019): entrevista realizada com o Supervisor de Trânsito Y. Entrevistador: Edson Celino Rodrigues Filho.
}

Geopauta, Vitória da Conquista, ISSN: 2594-5033, V. 5, n.1, 2021, e8057 
Trânsito está comprometida com as tarefas que decorrem desse tipo de fiscalização. Segundo a SEMOB,

[...] com o videomonitoramento, inevitavelmente irá aumentar o número de infrações, o que irá se refletir aqui no balcão. No balcão também vai refletir no setor de processamento de dados, para analisar e armazenar esses dados. O que acaba refletindo na coordenação (de trânsito) como um todo, pois tudo está envolvido. (INFORMAÇÃO VERBAL) ${ }^{7}$

Sobre as motivações para a implantação de um Projeto desse porte, a busca pela fluidez do trânsito foi o principal motivador para tal decisão. Segundo as entrevistas, um dos maiores problemas do trânsito conquistense é o volume de veículos que trafegam pela cidade. De acordo com Vasconcellos (2017) e Nemade (2016), problemas dessa natureza se devem aos conflitos físicos, que impedem que as necessidades de deslocamento, parada e estacionamento sejam atendidas ao mesmo tempo.

Outro fator determinante para a implantação do Projeto refere-se ao texto contido nos parágrafos $2^{\circ}, 3^{\circ}$ e $5^{\circ}$ do $1^{\circ}$ artigo do CTB: um trânsito seguro é direito de todos e os órgãos pertencentes ao Sistema Nacional de Trânsito (SNT) devem adotar as medidas para garantir esse direito; os órgãos contidos no SNT são diretamente responsáveis pelos danos causados aos cidadãos e os órgãos componentes do SNT devem dar preferência de suas ações à defesa da vida, conservação da saúde e preservação do meio ambiente (BRASIL, 1997).

Segundo Bastos, Andrade e Cordoni (1999), o aumento nos casos de violência no trânsito está diretamente relacionado à falta de fiscalização. Para o SIMTRANS, desde o início da primeira etapa do Projeto de Videomonitoramento, houve uma grande redução na incidência de infrações de trânsito nas vias próximas ao prédio da Prefeitura Municipal (local onde se implantou as primeiras câmeras), validando ainda mais a premissa de que é necessária uma fiscalização permanente e incisiva para que haja uma maior educação e segurança no trânsito.

\footnotetext{
${ }^{7}$ IDEM
} 
Para identificar o efeito disciplinar esperado com a implantação do Projeto de Videomonitoramento do Trânsito, analisou-se os dados obtidos e verficou-se que, para o SIMTRANS, o efeito disciplinar esperado é a inibição dos casos de infração de trânsito, uma vez que os condutores passam a controlar suas ações em ambientes monitorados. Segundo a SEMOB,

[...] o certo é o condutor evitar cometer qualquer imprudência, não somente nos trechos monitorados e não trafegar com velocidades superiores à permitida nas vias, não furar sinal vermelho, não estacionar em local proibido e esperar também que o outro não fará a mesma coisa (INFORMAÇÃO VERBAL). ${ }^{8}$

Tal raciocínio se assemelha ao que é tratado nos estudos de Haerter (2012), pois os mecanismos de controle social agem para tentar, de alguma forma, prever e coibir casos de "desvio social", procurando reduzir significativamente os índices de desrespeito às leis, neste caso, as leis de trânsito.

As gravações de vídeo registraram 749 casos de infrações de trânsito em 555 minutos de gravação (Quadro 1). Ou seja, um número aproximado de 1,3 infrações por minuto. O número de infrações de trânsito observadas, porém, pode ter sido superior, pois esse se refere apenas às imagens que puderam ser visualizadas nas imagens gravadas durante a pesquisa. Isso confirma a importância do uso de câmeras de VDM para identificação de infrações de trânsito, assim como da sua contribuição no sentido de coibir a ocorrência de atos infracionários (BASTOS; ANDRADE; CORDONI, 1999; VASCONCELLOS, 2017).

Quadro 1 - Relação das infrações identificadas por meio de gravação de vídeo em vias monitoradas e não monitoras pela PMVC.

\begin{tabular}{|l|l|l|}
\hline CTB & № de casos & Descrição da infração \\
\hline Art. 181 & 435 & Estacionar veículo irregularmente \\
\hline Art. 182 & 10 & Parar veículo irregularmente \\
\hline Art. 183 & 3 & Parar o veículo sobre a faixa de pedestres \\
\hline Art. 186 & 22 & Transitar pela contramão de direção \\
\hline Art. 192 & 29 & $\begin{array}{l}\text { Deixar de guardar distância de segurança lateral e frontal entre os } \\
\text { veículos, bem como em relação ao bordo da pista, considerando-se a } \\
\text { velocidade, as condições climáticas do local da circulação e do veículo }\end{array}$ \\
\hline
\end{tabular}

\footnotetext{
${ }^{8}$ IDEM IBIDEM
}

Geopauta, Vitória da Conquista, ISSN: 2594-5033, V. 5, n.1, 2021, e8057 


\begin{tabular}{|c|c|c|}
\hline Art. 193 & 9 & $\begin{array}{l}\text { Transitar com o veículo em calçadas, passeios, ciclovias, ciclofaixas, } \\
\text { ajardinamentos, canteiros centrais e divisores de pista de rolamento, } \\
\text { acostamentos, marcas de canalização, gramados e jardins públicos }\end{array}$ \\
\hline Art. 196 & 59 & $\begin{array}{l}\text { Deixar de indicar com antecedência, mediante gesto regulamentar de } \\
\text { braço ou luz indicadora de direção, o início da marcha, a realização da } \\
\text { manobra de parar o veículo, a mudança de direção ou de faixa }\end{array}$ \\
\hline Art. 199 & 17 & $\begin{array}{l}\text { Ultrapassar pela direita, salvo quando o veículo da frente estiver } \\
\text { colocado na faixa apropriada e der sinal de que vai entrar à esquerda }\end{array}$ \\
\hline Art. 206 & 4 & $\begin{array}{l}\text { Executar operação de retorno em local proibido ou que cause prejuízo } \\
\text { à livre circulação ou segurança mesmo em locais permitidos }\end{array}$ \\
\hline Art. 208 & 22 & Avançar o sinal vermelho do semáforo ou o de parada obrigatória \\
\hline Art. 214 & 4 & Deixar de dar preferência a pedestre e veículo não motorizado \\
\hline Art. 215 & 2 & Deixar de dar preferência de passagem \\
\hline Art. 244 & 8 & $\begin{array}{l}\text { Conduzir motocicleta, motoneta e ciclomotor: I - sem usar capacete de } \\
\text { segurança com viseira ou óculos de proteção e vestuário de acordo } \\
\text { com as normas e especificações aprovadas pelo CONTRAN }\end{array}$ \\
\hline Art. 250 & 2 & $\begin{array}{l}\text { Deixar de manter acesa a luz baixa, durante a noite, quando o veículo } \\
\text { estiver em movimento. }\end{array}$ \\
\hline Art. 252 & 7 & $\begin{array}{l}\text { Dirigir o veículo com o braço do lado de fora e com apenas uma das } \\
\text { mãos, exceto quando deva fazer sinais regulamentares de braço, } \\
\text { mudar a marcha do veículo, ou acionar equipamentos e acessórios do } \\
\text { veículo. Caracterizar-se-á como infração gravíssima no caso de o } \\
\text { condutor estar segurando ou manuseando telefone celular }\end{array}$ \\
\hline Art. 254 & 96 & $\begin{array}{l}\text { É proibido ao pedestre: I - permanecer ou andar nas pistas de } \\
\text { rolamento, exceto para cruzá-las onde for permitido }\end{array}$ \\
\hline Art. 58 & 20 & $\begin{array}{l}\text { Nas vias urbanas e nas rurais de pista dupla, a circulação de bicicletas } \\
\text { deverá ocorrer, quando não houver ciclovia, ciclofaixa, ou } \\
\text { acostamento, ou quando não for possível a utilização destes, nos } \\
\text { bordos da pista de rolamento, no mesmo sentido de circulação } \\
\text { regulamentado para a via, com preferência sobre os veículos } \\
\text { automotores }\end{array}$ \\
\hline TOTAL & 749 & \\
\hline
\end{tabular}

Fonte: Dados da pesquisa (2019).

A partir do resultado da coleta de dados da pesquisa, verificou-se que a incidência dos casos de infrações de trânsito no trecho monitorado é muito menor que nos pontos não monitorados, uma vez que apenas 54 dos 749 casos de infrações foram identificados nas vias que possuem VDM de trânsito, representando somente 7,2\% dos casos apresentados. Esses dados têm relação com as críticas apontadas por Cupolillo (2006) e Lopes e Porto (2007), ao defenderem que a fiscalização eletrônica possui 
caráter local, restringindo-se aos locais monitorados, o que permite aos infratores praticarem as más condutas onde não há fiscalização.

Evidencia-se que, segundo o Quadro 2, cerca de 58\% das infrações observadas referem-se ao que define o Art. 181 do CTB, sobre o estacionamento irregular de veículos. Esse dado está de acordo com as entrevistas realizadas com os representantes da SEMOB, que revelaram que a infração mais identificada pelas câmeras de monitoramento instaladas no entorno do prédio da Prefeitura Municipal, na primeira fase do Projeto, foi relacionada ao Art. 181: “As infrações mais cometidas foram aquelas relacionadas ao Art. 181 do CTB, né? Que vai falar sobre a questão do estacionamento. Estacionar ao lado de canteiro central, estacionar em área de canalização, em suma, estacionar onde é proibido" (INFORMAÇÃO VERBAL) ${ }^{9}$.

Os dados confirmam que os cidadãos estão cientes dos prejuízos causados por aqueles que insistem em cometer infrações, sobretudo, em benefício próprio. Esse achado tem relação com a definição de conflito político proposta por Vasconcellos (2017), uma vez que tais conflitos são causados pela diferente posição ocupada por cada pessoa no processo produtivo e seus impactos para a sociedade. O debate proposto por DaMatta (2015), ao tratar do "jeitinho brasileiro" presente em alguns atores sociais, quando impõe suas vontades aos demais, em função de sua posição social, sem se preocupar com as consequências de suas ações, pode contribuir para a compreensão desses achados. Em contraponto, o uso dos mecanismos de controle social, sob a forma de câmeras de monitoramento, age como preconiza a abordagem funcionalista: como meras repressoras para se manter a ordem, frente às ameaças impostas à sociedade, não dando atenção aos reais motivos que levam os infratores a praticarem as más condutas no trânsito.

\footnotetext{
${ }^{9}$ Entrevista I (Março de 2019): entrevista realizada com o Agente de Trânsito X. Entrevistador: Edson Celino Rodrigues Filho.
}

Geopauta, Vitória da Conquista, ISSN: 2594-5033, V. 5, n.1, 2021, e8057 
Painel 1- Infração ao Art. 252, Alínea V, agravada pelo uso de telefone cellular (esquerda) e Pedestres caminhando e correndo fora da calçada na Avenida Olívia Flores (direita).

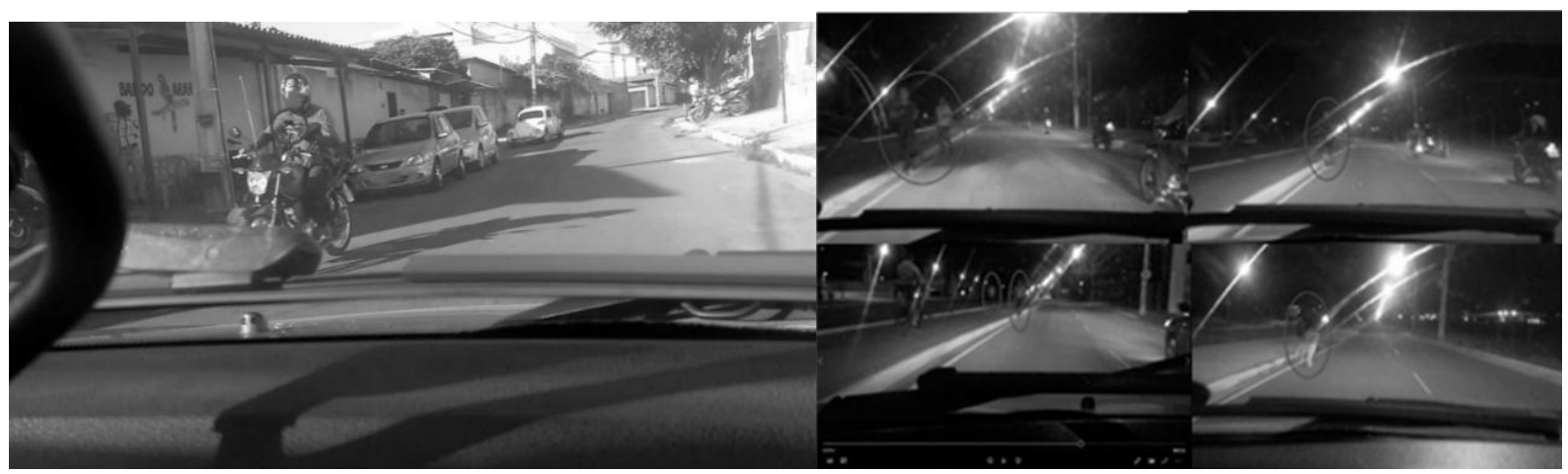

Fonte: Dados da pesquisa de campo. Foto: Edson Celino Rodrigues Filho (Fevereiro de 2019)

Quanto ao elevado número de infrações, não foram incluídas o número total das infrações de pessoas que conduziam veículos utilizando o aparelho celular, porque o ângulo em que se encontrava a câmera responsável pelos registros não permitia tal visualização com clareza. Observou-se, porém, alto número de pessoas que conduziam seus veículos usando celular, inclusive motociclistas, como pode ser observado na Foto acima a esqerda. Tal uso, combinado com a direção, gera a distração que, pode, assim, provocar acidentes e envolver vítimas (SCHICK et al., 2014).

Quanto aos pedestres, responsáveis por aproximadamente $12,8 \%$ dos casos de infrações observadas na pesquisa, verificou-se a falta de bom senso em utilizar as calçadas para se deslocar. A Avenida Olívia Flores, uma das mais importantes da cidade, é palco dessa infração, sendo comumente utilizada pelos pedestres conquistenses para a prática de atividades físicas, como caminhada e corrida. Todavia, pedestres usam a faixa exclusiva dos ciclistas, forçando-os a trafegar junto aos veículos motorizados. Ademais, utilizam-se, irregularmente, faixas destinadas ao tráfego de ciclistas e também de veículos motorizados por pessoas praticando caminhada e corrida (Foto acima a direita), ainda que haja local destinado a tal prática na referida avenida.

Os dados coletados revelam que o trânsito conquistense é repleto de más condutas praticadas pelos seus vários atores. A maioria das infrações observadas, 
representando $92,4 \%$ das ocorrências, foi flagrada em trechos não monitorados, o que reforça a ideia de que o uso de tais mecanismos de fiscalização reduz significativamente os índices de infração de trânsito, atingindo o efeito disciplinar esperado pela sua utilização (HAERTER, 2012).

Sobre os critérios de ampliação de projetos de fiscalização eletrônica na área urbana de Vitória da Conquista, não foi descartado o uso dos radares de medição de velocidade e demais equipamentos nos trechos mais críticos pelo órgão municipal de trânsito. Segundo o Supervisor Y, “o Projeto ainda prevê futuramente, não só o VDM, como também radares, que estão sendo feitos estudos em avenidas como a Brumado e Luís Eduardo Magalhães". Medidas como essa demonstram o interesse na redução dos números de acidentes relacionados ao excesso de velocidade em vias críticas.

Cupolillo (2006) e Lopes e Porto (2007) defendem que os mecanismos eletrônicos de fiscalização do trânsito são ferramentas promotoras de punição, ao invés de educação. Em se tratando das autuações, que, consequentemente, geram multas para os infratores, a população considera que tais mecanismos fomentam a ideia da "indústria das multas". No entanto, o Gráfico 1 revela que as opiniões são bastante diversificadas.

Gráfico 1 - Percepção do uso do VDM como fomentador da distribuição de multas de trânsito

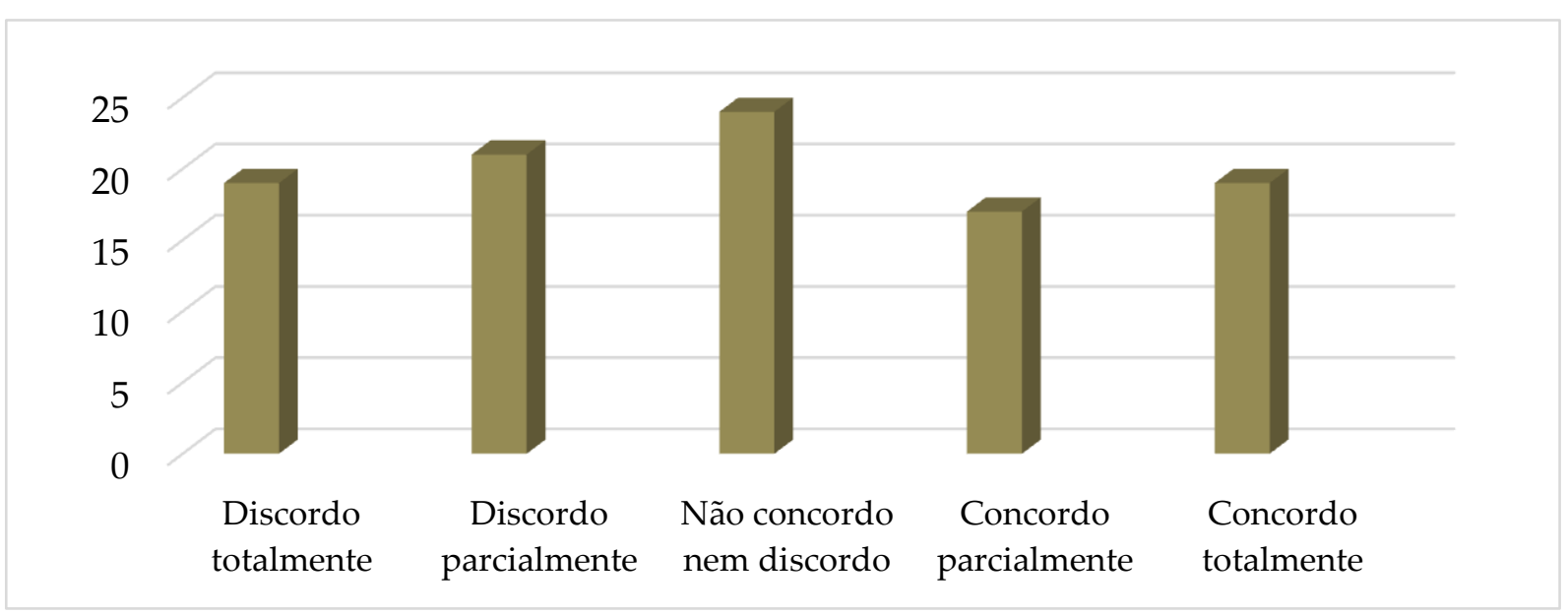

Fonte: Dados da pesquisa (2019).

Para a SEMOB, a intenção da fiscalização eletrônica não é multar e arrecadar, mas promover um trânsito mais seguro para todos. Para os entrevistados, as multas 
são meras consequências das más condutas dos condutores que não seguem as leis de trânsito.

\begin{abstract}
Alguns acham que esse Projeto só existe para autuar. Porém, essa arrecadação não é como se imagina. O prazo comum para se receber após uma autuação, gira em torno de 18 a 20 meses. Sem contar o fato que dessas autuações, cerca de $40 \%$ não são pagas. E das que são pagas, só começam a ser pagas de 1 a 2 anos. E desse montante que é pago, você tem que lembrar que tiveram os custos [...] ao chegar como arrecadação na Prefeitura é cerca de 50\% do valor. Além de que, pelo que prega o CTB, todo o dinheiro arrecadado em função do trânsito, fica no trânsito. Para custear obras viárias, infraestrutura, educação para o trânsito. Em relação a "Indústria das multas", basta não cometer infrações. Claro que podem haver erros também, pois são humanos que estão por traz da máquina, para isso existe a possibilidade de recorrer das multas. Porém, quem foi multado, a grande maioria admite o erro, afinal não tem o que discutir. (INFORMAÇÃO VERBAL $)^{10}$
\end{abstract}

O Quadro 2 apresenta a percepção geral dos indivíduos sobre o trânsito da cidade e da atuação dos órgãos de fiscalização. Para isto, as respostas de uma das questões do questionário aplicado à população foram categorizadas para avaliar a opinião global dos respondentes sobre alguns temas pertinentes ao estudo.

Quadro 2 - Percepção da população a respeito do trânsito e da atuação da SEMOB

\begin{tabular}{|l|c|c|c|}
\hline \multicolumn{1}{|c|}{ Tema } & $\begin{array}{c}\text { Percepção } \\
\text { negativa (\%) }\end{array}$ & $\begin{array}{c}\text { Neutralidade } \\
(\%)\end{array}$ & $\begin{array}{c}\text { Percepção } \\
\text { positiva (\%) }\end{array}$ \\
\hline $\begin{array}{l}\text { Percepção sobre a condição e segurança } \\
\text { das vias e calçadas }\end{array}$ & 76 & 10 & 14 \\
\hline Percepção sobre a condição da sinalização & 52,5 & 21,5 & 26 \\
\hline $\begin{array}{l}\text { Percepção do comportamento dos usuários } \\
\text { do trânsito (condutores, pedestres, etc.) }\end{array}$ & 58,3 & 12,7 & 29 \\
\hline $\begin{array}{l}\text { Percepção da fiscalização } \\
\text { Percepção sobre a atuação dos órgãos } \\
\text { competentes pelo trânsito }\end{array}$ & 49,3 & 22 & 28,7 \\
\hline Percepção sobre o VDM do trânsito & 30 & 16,4 & 42,1 \\
\hline
\end{tabular}

Fonte: Dados da pesquisa (2019)

\footnotetext{
${ }^{10}$ Entrevista III (03.2019): entrevista realizada com o Coordenador de Trânsito Z. Entrevistador: Edson Celino Rodrigues Filho
}

Geopauta, Vitória da Conquista, ISSN: 2594-5033, V. 5, n.1, 2021, e8057 
Para a população, os impactos trazidos por esse novo modelo de fiscalização são positivos, pois 53\% dos respondentes detêm uma percepção positiva em relação ao emprego de tais mecanismos no trânsito da cidade (Quadro 2). Entretanto, na opinião das pessoas indagadas, o maior problema de trânsito da cidade deriva das péssimas condições das vias e da deficiente sinalização. Tais condições, aliadas às más condutas dos indivíduos, podem repercutir em um trânsito desorganizado e perigoso (FERREIRA; TEBALDI, 2004). Esse resultado pode explicar o índice de aprovação do VDM, apesar do número de opiniões contrárias ainda ser expressivo (30\%), conforme observado no Quadro 2. Vale salientar que, mesmo as respostas sobre a atuação dos órgãos competentes se mostrarem razoavelmente equilibradas, um ponto bastante criticado pela população foi a falta de investimento, por parte do poder público, em treinamento e educação para o trânsito praticado em prol dos cidadãos, contrariando o que preconiza Silva (2002) sobre a importância da educação como principal ferramenta de conscientização dos cidadãos para um convívio harmonioso e seguro no trânsito.

Em síntese, os resultados indicam um vislumbre de esperança em torno das inovações tecnológicas usadas para desenvolver a segurança e a fluidez do tráfego de veículos e pessoas na cidade, mesmo ainda oferecendo resistência.

\section{Considerações Finais}

Os inúmeros problemas causados pelas más condutas no trânsito estimulam o avanço das tecnologias que visam controlar e tornar o trânsito um espaço mais humano e seguro, inclusive, outras localidades no vasto território nacional podem, assim como Vitória da Conquista, estar vivenciando tais desafios e implantando ou até mesmo estudando a possibilidade de instalar mecanismos de controle do trânsito. Por isso, as ações dos órgãos competentes estão cada vez mais voltadas para o controle através do uso de mecanismos de fiscalização eletrônica, que tentam reduzir os altos números de acidentes e vítimas do trânsito.

A Secretaria de Mobilidade Urbana (SEMOB), ou SIMTRANS como é popularmente conhecida pelos moradores de Vitória da Conquista, possui um sistema Geopauta, Vitória da Conquista, ISSN: 2594-5033, V. 5, n.1, 2021, e8057 
de informações sobre o trânsito capaz de armazenar e tratar os dados oriundos das ocorrências que se sucedem diariamente no trecho urbano. No entanto, devido ao caráter recente do Projeto de Videomonitoramento do Trânsito do município, ainda não há estatísticas de comparação a períodos anteriores que permitam confirmar se houve melhorias no trânsito propriamente dito.

Os dados coletados revelaram que o projeto de fiscalização eletrônica para o trânsito de Vitória da Conquista, implantado pela SEMOB, foi motivado, principalmente, pela busca da melhoria na fluidez do trânsito, sobretudo, no centro da cidade, marcado pela crescente necessidade de garantir a boa circulação do grande número de veículos e pedestres que trafegam na região central, diariamente, e pelo aumento da segurança e do cumprimento das leis do Código de Trânsito Brasileiro.

Segundo a SEMOB, pôde-se aferir, ainda, que a incidência de infrações nos trechos monitorados se manteve extremamente baixa em relação aos trechos nãomonitorados, alcançando a proporção de pelo menos nove para um se compararmos o índice de infrações entre os ambientes não monitorados e monitorados.

Quanto às as expectativas da população e do poder público municipal a respeito da implantação de dispositivos de fiscalização eletrônica no trânsito conquistense, foi possível verificar que tanto o Poder Público quanto a população esperam que a adoção de tais mecanismos provoque mudanças significativas e positivas no comportamento das pessoas no trânsito. Porém, muitas opiniões expressam a preocupação com o fato de essa ferramenta ser usada somente como meio de arrecadação. Os órgãos reguladores negam tal intenção e defendem que o Projeto prevê melhorias para a fluidez e a segurança do trânsito da cidade, promovendo mudanças benéficas para toda a população.

A atual pesquisa se apresenta como o exórdio de estudos sobre o uso dos equipamentos de VDM no trânsito em uma cidade de médio porte do interior baiano e se propõe a provocar o debate e a investigação sobre o assunto, logo que não deu conta de esgotar o tema em questão. Como agenda para futuros trabalhos, sugere-se a 
análise de dados estatísticos que possam enriquecer ainda mais os conhecimentos das ciências sociais aplicadas e verificar as contribuições alcançadas com as novas técnicas de controle, independente do âmbito social.

\section{Referências}

ALCADIPANI, R.; MOTTA, F. C. P. Jeitinho brasileiro, controle social e competição. RAE., São Paulo, v. 39, n. 1, p. 6 - 12, mar. 1999. Disponível em: <http://www.scielo. br/scielo.php?script=sci_arttext\&pid=S0034-=en\&nrmiso>. Acesso em: 18 set. 2018.

ALENCAR, E. Introdução à metodologia de pesquisa social. Lavras: UFLA, 1999.

ALVES, P.; FERREIRA, W. R. Mobilidade Urbana e TrafficCalming. Revista Caminhos de Geografia, Uberlândia, v. 15, n. 51, p. 60-72, set. 2014. Disponível em: <http://www.seer.ufu.br/index.php/article/15459>. Acesso em: 25 set. 2018.

BARTHÉLEMY, J. et al. Edge-Computing Video Analytics for Real-Time Traffic Monitoring in a Smart City, Sensors, Suíça. v. 19, n. 2048, 2019. Disponível em: <https://www.mdpi.com/1424-8220/19/9/2048/htm>. Acesso em: 13 mar. 2020.

BASTOS, Y. G. L.; ANDRADE, S. M.; CORDONI, L. J. Acidentes de trânsito e o novo CTB em Cidades do Sul do Brasil. Inf. Epidemiol. Sus, Brasília, v. 8, n. 2, p. 37-45, jun. 1999. Disponível em: <http://scielo.iec.gov.br/>. Acesso em: 17 set. 2018.

BONI, V.; QUARESMA, S. J. Aprendendo a entrevistar: como fazer entrevistas em ciências sociais. Em Tese, Florianópolis, v. 2, n. 1, p. 68-80, jan. 2005.

BRASIL. Código de Trânsito Brasileiro. Brasília: Presidência da República, 1997.

BRASIL. Resolução no 471, de 18 de dezembro de 2013. Regulamenta a fiscalização de trânsito por intermédio de videomonitoramento. Lex: Ministério das Cidades e Conselho Nacional de Trânsito, Brasília, 2013.

BRASIL. Estimativa dos Custos dos Acidentes de Trânsito com Base na Atualização Simplificada das Pesquisas Anteriores do Ipea. Brasília: IPEA, 2015.

BRICALLI, I. L.; ZANOTELLI, C. L. A fragilização dos espaços públicos a partir da utilização de câmeras de vigilância na cidade de Vila Velha (ES). Geo UERJ, Rio de Janeiro, n. 29, p. 133-169, nov. 2016. Disponível em: <http://www.e-publicacoes.uerj. br/index.php/geouerj/article/view/16928>. Acesso em: 18 set. 2018.

CASTRO, R. B.; PEDRO, R. M. L. R. Experiências da vigilância: subjetividade e sociabilidade articuladas ao monitoramento urbano. Psicol. Soc., Belo Horizonte, v. 
25, n. 2, p. 353-361, 2013. Disponível em: <http://www.scielo.br/scielo.php?script= sci_arttext\&pid=S0102-718220130012\&lng=en\&nrm=iso>. Acesso em: 04 out. 2018.

CONTROLE. In: Dicionário online Michaelis, Editora Melhoramentos, 2018.

CUPOLILLO, M. T. A. Estudos das medidas moderadoras do tráfego para controle da velocidade e dos conflitos em travessias urbanas. 2006. 287f. Dissertação (Mestrado em Engenharia de Transportes) - UFRJ, Rio de Janeiro, 2006.

DAMATTA, Roberto. Carnavais, malandros e heróis: para uma sociologia do dilema brasileiro. 5ํㅜ ed. Rio de Janeiro: Rocco Digital, 2015.

DEMO, P. Pesquisa e construção do conhecimento: metodologia científica no caminho de Habermas. Rio de Janeiro: Tempo Brasileiro, 1994.

FERREIRA, V. R. T.; TEBALDI. E. Comportamentos no trânsito e causas da agressividade. Revista de Psicologia da UnC, v. 2, n. 1, p. 15-22, 2004. Disponível em: $<$ https://www.researchgate.net/profile/Vinicius. pdf >. Acesso em: 15 set. 2018.

FRANZ, C. M.; SEBERINO, J. R. V. A história do trânsito e sua evolução. 2012. Monografia (Pós-graduação em Gestão, Educação e Trânsito), Joinville, 2012.

GAZIR, A. Trombada histórica: Olavo Bilac era motorista no primeiro acidente do RJ. Folha de São Paulo, Brasília, 22 jan. 1998. Disponível em: <https://www1.folha. uol.com.br/fsp/especial/fj220116.htm>. Acesso em: 13 set. 2018.

GIL, A. C. Métodos e técnicas de pesquisa social. 6ª ed. São Paulo: Atlas, 2011.

HAERTER, L. O conceito de controle social nos olhares estruturalista, funcionalista, fenomenológico e interacionista. Cadernos de Campo: Revista de Ciências Sociais, Araraquara, n. 16, p. 21-35, 2012. Disponível em: <https://periodicos.fclar. unesp.br/cadernos/article/view/7314>. Acesso em: 18 set. 2018.

HOFFMANN, M. H.; CRUZ, R. M.; ALCHIERI, J. C. (Org.). Comportamento humano no trânsito. $1^{a}$ ed. São Paulo: Casa do Psicólogo, 2003. 406 p.

LOPES, M. M. B.; PORTO, W. J. Fiscalização eletrônica da velocidade de veículos no trânsito: caso de Niterói. In: CONGRESSO LATINO-AMERICANO TRANSPORTE PÚBLICO E URBANO, 14., 2007, Rio de Janeiro. Anais... Rio de Janeiro, 2007.

NEMADE, B. Automatic Traffic Surveillance Using Video Tracking. Procedia Computer Science, v. 79, p. 402-409, 2016. Disponível em: <https://www.sciencedi rect.com/science/article/pii/S1877050916001836>. Acesso em: 10 mai. 2020.

MERTON, R. K. Social Theory and Social Structure. New York: Free Press, 1968.

PMVC. Prefeitura implanta sistema de videomonitoramento. 2018. Disponível em: http://www.pmvc.ba.gov. Acesso em: 03 out. 2018. 
ROSS, E. A. Social Control. Nova Iorque: New Routledge, 2017.

SCARINGELLA, R. S. A crise da mobilidade urbana em São Paulo. São Paulo em Perspectiva, São Paulo, v. 15, n. 1, p. 55-59, jan. 2001.

SCHICK, A. et al. Distraction by cell phones and texting. Washington: NHTSA, 2014. Disponível em: https://www.nhtsa.gov/. Acesso em: 25 mai. 2020.

SILVA, F. C. C. Controle social: reformando a administração para a sociedade. Organ. Soc., Salvador, v. 9, n. 24, p. 115-137, Ago. 2002.

SOUSA, M. C. Fiscalização Eletrônica: análise da eficácia na redução dos acidentes de trânsito - Uberlândia 2004 a 2006. 2008. 217 p. Dissertação (Mestrado em Geografia) Universidade Federal de Uberlândia, Uberlândia, 2008.

VASCONCELOS, E. A. O que é trânsito. São Paulo: Editora Brasiliense, 2017.

YIN, R. K. Case Study Research: design and methods. 4aa ed. Califórnia: SAGE, 2009.

Contribuição dos autores: Edson Celino Rodrigues Filho: Elaboração, Coleta e interpretação dos dados discussão dos resultados, pesquisa bibliográfica

Almiralva Ferraz Gomes: Supervisão, desenvolvimento da pesquisa e revisão do texto. Rita de Cássia Oliveira Lima Alves: Interpretação dos dados; supervisão e revisão do texto. 